\title{
Drivers of transactional sexual relationships among students in a Nigerian University: implications for elimination of reproductive rights violation
}

\author{
Oluwatosin Sunday Ige, Bola Lukman Solanke*
}

Department of Demography and Social Statistics Obafemi Awolowo University Ile-Ife, Nigeria

Received: 05 October 2020

Revised: 12 November 2020

Accepted: 13 November 2020

*Correspondence:

Dr. Bola Lukman Solanke,

E-mail: bsolanke@ oauife.edu.ng

Copyright: () the author(s), publisher and licensee Medip Academy. This is an open-access article distributed under the terms of the Creative Commons Attribution Non-Commercial License, which permits unrestricted non-commercial use, distribution, and reproduction in any medium, provided the original work is properly cited.

\begin{abstract}
Background: The objective of the study was to assess the prevalence and drivers of transactional sex in a Nigerian University.

Methods: Data was collected through Mobile Data Collection platform (Google form). The dependent variable was transactional sex. The independent variables are self-reported household wealth group, gender, current age, marital status, age at sexual debut, family structure, consumption of alcohol, and use of psychoactive drugs. Two binary logistic regression models were fitted.

Results: The prevalence of transactional sex was $23.85 \%$. The odds of transactional sex were higher among females $(\mathrm{OR}=1.642,95 \% \mathrm{CI}: 1.499-1.799)$ and older students, but lower among undergraduates who were 18 years or older at the time of first intercourse $(\mathrm{OR}=0.842,95 \% \mathrm{CI}$ : $0.764-0.927)$. Results further revealed that while being from richest household wealth group $(\mathrm{OR}=0.587,95 \% \mathrm{CI}$ : $0.486-0.710)$ and being from a nuclear family structure $(\mathrm{OR}=0.446$, 95\% CI: $0.213-0.933$ ) lowers the odds of transactional sex, the use of psychoactive drugs and alcoholic consumption increased the likelihood of transactional sex among undergraduates.

Conclusions: The drivers of transactional sex in tertiary institutions in Nigeria are age, age at sexual debut, family structure, use of psychoactive drugs and alcoholic consumption. Promoting responsible sexual behaviour of undergraduates is imperative in the country.
\end{abstract}

Keywords: Nigeria, Sexual and reproductive health, Transactional sex, Young people

\section{INTRODUCTION}

Transactional sexual relationships are non-commercial relationships in which sex is demanded mostly by men and exchanged for cash, goods, services, commodities, or privileges mostly by women for the purpose of meeting the needs of men and women involved in the relationships. $^{1,2}$ Transactional sexual relationships has been widely reported across the world and linked to several adverse sexual and reproductive health outcomes such as increasing sexually transmitted infections including HIV/AIDS and intimate partner violence and several socio-economic exploitative practices. $^{3-15}$ Its continued prevalence in tertiary institutions of learning across the world requires further research into the possible drivers for two important reasons.,.$^{3,16,18}$ One, transactional sex within academic institutions erode the credibility of scholarship and promotes mediocrity which endangers national development in the long run. Two, transactional sex is a harmful practice that violates the sexual and reproductive rights of young girls involved because the circumstances of such sexual relationships do 
not empower girls or women to negotiate safer sex. Studies have documented the drivers of transactional sexual relationships. A number of studies reported that young people particularly young women practice transactional sex due to economic factors. ${ }^{12,13,19-20}$ Many desire to escape poverty; many are in need of cars, cash, expensive clothes and phones and agree to exchanging sex as means of meeting their needs. Another widely reported reason for transactional sex is the widespread phenomenon of 'Sugar Daddy or Aristo' which refers to the patronage of rich men by young girls in order to acquire very expensive material things. ${ }^{3,11,17}$ Studies have also reported that transactional sex thrives due to the practice of intergenerational sexual relationships. ${ }^{21-23}$ Such sexual relationships often undermine the ability of young women to negotiate safer sex, thus elevating their vulnerability to unintended pregnancy and unsafe abortion. A recent study argue that gendered expectation that men should always be the one to provide economic resources in a relationship while women reciprocate with sex may be a driver of transactional sex in the society particularly in sub-Saharan Africa. ${ }^{14}$ However, studies have not documented these drivers in some Nigerian Universities, hence this study. The objective of the study was therefore to assess the prevalence and drivers of transactional sex in a Nigerian University. Findings from the study will provide further inputs for strengthening of the 2017 National Reproductive Health Policy in Nigeria by providing additional information on harmful practices that violates the sexual and reproductive health of Undergraduates in the country. ${ }^{24}$ The study was guided by the question what are the drivers of transactional sex?

\section{METHODS}

This study was a descriptive cross-sectional research study which sought information from respondents through the Mobile Data Collection platform (Google form), a tool that allows collecting information from users via a personalized survey or quiz. Information collected was automatically connected to a spreadsheet. The spreadsheet was populated with the survey and quiz responses.

The target populations for the study were the undergraduate students of Obafemi Awolowo University, Ile-Ife, Nigeria. The University lies between Longitude $4^{\circ} 31^{\prime} 1.427^{\prime \prime}$ East, and $7^{\circ} 31^{\prime} 32.153^{\prime \prime}$ North and Latitude $4^{\circ} 31^{\prime} 50.165^{\prime \prime}$ East and $7^{\circ} 31^{\prime} 31.869^{\prime \prime}$ North and bordered on all sides by Ile-Ife town, a prominent city in southwest Nigeria. The study was conducted in November 2019 and analysed a sample size of two hundred and thirty nine respondents (239) students who completed and returned the survey questionnaire.

\section{Selection criteria and procedure}

Students selected into the study are those who owned an Android phone and consented to participate in the study. A non-probabilistic sampling technique was employed to select a sample size of two hundred and thirty nine respondents (239) from the study area. The samples were respondents who were readily available and willing to participate in the online survey. Evidence of spreadsheet for collection of data attached.

\section{Research variables}

The dependent variable for the study was transactional sex. To capture data on transactional sex in the study, respondents were asked if in the last 12 months if they had entered into a sexual relationship with a non-sex worker mainly to get some items such as cash, gifts, phones, or other needed things important to them. The responses were dichotomous with yes indicating transactional sex practice and no indicating otherwise. The independent variables for this study are self-reported household wealth group (poorer, middle, richer, richest), gender (male or female), current age (15-19, 20-24, 25 years or older), marital status (cohabiting, married, never married), age at sexual debut (less than 18 years or 18 years or older), family structure (foster, nuclear, polygynous, single-parent), consumption of alcohol (yes or no) in the last three months, and use of psychoactive drugs such as cannabis and tobacco (yes or no) in the last three months preceding the survey. These variables have been identified as covariates of transactional sex and other risky sexual behaviour among young people in the country. ${ }^{7,25,26}$

\section{Statistical analysis}

Data were analysed using frequency distribution and percentages. Two binary logistic regression models were fitted to determine the variables influencing transactional sex among the undergraduates. Model 1 was unadjusted. Any variable not showing statistical significance in the model was excluded from Model 2. Statistical significance was set at $\mathrm{p}<0.05$. All analyses were performed using Stata (Version 14). ${ }^{27}$

\section{Ethical approval}

The study was conducted as part of the requirements for the award of a Bachelor of Science Degree in the Department of Demography and Social Statistics. The survey protocol was assessed and approved by the Department. The analyses are done anonymously.

\section{RESULTS}

Table 1 presents respondents' profile. More than half $(53.14 \%)$ of the respondents were males but the proportion of females in the sample was equally substantial. The dominant $(44.35 \%)$ age group among the respondents was the age group 20-24 years. The majority $(73.22 \%)$ of the students had their first sexual intercourse at age eighteen or older ages. Likewise, the majority $(86.20 \%)$ of the students were never married. The 
majority $(79.50 \%)$ also reported residing in households in the middle wealth group.

Table 1: Socio-demographic characteristics of respondents.

\begin{tabular}{|c|c|c|}
\hline Characteristic & Frequency & Percentage \\
\hline \multicolumn{3}{|l|}{ Gender } \\
\hline Male & 127 & 53.14 \\
\hline Female & 112 & 46.86 \\
\hline \multicolumn{3}{|l|}{ Age } \\
\hline $15-19$ years & 72 & 30.13 \\
\hline 20-24 years & 106 & 44.35 \\
\hline 25 years + & 61 & 25.52 \\
\hline \multicolumn{3}{|l|}{ Age at sexual debut } \\
\hline Less than 18 years & 64 & 26.78 \\
\hline 18 years + & 175 & 73.22 \\
\hline \multicolumn{3}{|l|}{ Marital status } \\
\hline Cohabiting & 10 & 4.18 \\
\hline Married & 23 & 9.62 \\
\hline Never married & 206 & 86.20 \\
\hline \multicolumn{3}{|c|}{ Household wealth group } \\
\hline Poorer & 11 & 4.60 \\
\hline Middle & 190 & 79.50 \\
\hline Richer & 25 & 10.46 \\
\hline Richest & 13 & 5.44 \\
\hline \multicolumn{3}{|l|}{ Family structure } \\
\hline Foster & 20 & 8.37 \\
\hline Nuclear & 161 & 67.36 \\
\hline Polygynous & 27 & 11.30 \\
\hline Single-parent & 31 & 12.97 \\
\hline \multicolumn{3}{|c|}{ Psychoactive drug use } \\
\hline No & 198 & 82.85 \\
\hline Yes & 41 & 17.15 \\
\hline \multicolumn{3}{|c|}{ Alcoholic consumption } \\
\hline No & 184 & 79.99 \\
\hline Yes & 55 & 23.01 \\
\hline \multicolumn{3}{|l|}{ Transactional sex } \\
\hline No & 182 & 76.15 \\
\hline Yes & 57 & 23.85 \\
\hline Total & 239 & 100.00 \\
\hline
\end{tabular}

Source: Fieldwork, 2019
More than two-thirds $(67.36 \%)$ of the respondents had nuclear family structure. Less than one-fifth (17.15\%) had used at least one type of psychoactive drugs in the last three months while more than one-fifth $(23.01 \%)$ of the respondents had consumed alcoholic drink in the last three months preceding the survey. The prevalence of transactional sex was $23.85 \%$ among the respondents.

Table 2 presents the bivariable and multivariable results. In Model 1, all the independent variables with the exclusion of marital status revealed significant statistical associations with transactional sex. Marital status was thus excluded from further analysis. The full model (Model 2) showed that all the included variables had significant effect on the likelihood of transactional sex among the respondents. Females were $64.2 \%$ more likely to engage in transactional sex compared to male students $(\mathrm{OR}=1.642$, 95\% CI: 1.499-1.799). The odds of transactional sex increased with age of respondents though inconsistently. The odds were twice more higher among students aged 20-24 years $(\mathrm{OR}=2.059$, 95\% CI: 1.314-3.226) and as well twice higher among students age 25 years or older $(\mathrm{OR}=2.043,95 \% \mathrm{CI}: 1.181-3.532)$. In contrast, students who had first intercourse at age 18 or older were $15.8 \%$ less likely to experience transactional sex compared to those who had first intercourse at more younger ages $(\mathrm{OR}=0.842$, 95\% CI: $0.764-0.927)$.

As household wealth group improved from poorer to middle, the odds of transactional sex almost double $(\mathrm{OR}=1.980,95 \% \quad \mathrm{CI}: 1.605-2.443)$ but decline consistently thereafter. The odds were lower as household wealth group improved to the richest wealth group $(\mathrm{OR}=0.587$, 95\% CI: 0.486-0.710). While respondents from nuclear families had lower likelihood of engaging in transactional sex (OR=0.446, 95\% CI: 0.213-0.933), respondents from polygynous families $(\mathrm{OR}=1.782,95 \%$ CI: 1.440-2.204) and single-parent families $(\mathrm{OR}=2.882$, 95\% CI: 2.389-3.476) had higher odds of transactional sex. Respondents who had used psychoactive drugs were $78.2 \%$ more likely to engage in transactional sex compared to those who do not take the drugs $(\mathrm{OR}=1.782$, 95\% CI: 1.440-2.204). Likewise, respondents who had consumed alcoholic drinks were $35.9 \%$ more likely to engage in transactional sex $(\mathrm{OR}=1.359,95 \% \mathrm{CI}$ : 1.089 1.696)

Table 2: Results of bivariable and multivariable logistic regression models.

\begin{tabular}{|lllllll|}
\hline $\begin{array}{l}\text { Characteristic } \\
\text { predicting transactional } \\
\text { sex }\end{array}$ & Model 1 & & & \multicolumn{2}{l}{ Model 2 } & \\
\hline Gender & OR & p-value & 95\% CI & OR & p-value & 95\% CI \\
\hline Male ${ }^{\text {ref }}$ & 1.000 & - & - & 1.000 & - & - \\
\hline Female & 1.726 & $\mathrm{p}<0.01$ & $1.408-2.114$ & 1.642 & $\mathrm{p}<0.01$ & $1.499-1.799$ \\
\hline Age & & & & & & \\
\hline $15-19$ years ${ }^{\text {ref }}$ & 1.000 & - & - & 1.000 & - & - \\
\hline $20-24$ years & 3.157 & $\mathrm{p}<0.05$ & $1.043-9.557$ & 2.059 & $\mathrm{p}<0.05$ & $1.314-3.226$ \\
\hline 25 years + & 2.269 & $\mathrm{p}<0.01$ & $1.468-3.507$ & 2.043 & $\mathrm{p}<0.05$ & $1.181-3.532$ \\
\hline
\end{tabular}

Continued. 


\begin{tabular}{|c|c|c|c|c|c|c|}
\hline \multirow{2}{*}{$\begin{array}{l}\text { Characteristic } \\
\text { predicting transactional } \\
\text { sex }\end{array}$} & \multicolumn{3}{|l|}{ Model 1} & \multicolumn{3}{|c|}{ Model 2} \\
\hline & OR & p-value & $95 \% \mathrm{CI}$ & OR & p-value & $95 \% \mathrm{CI}$ \\
\hline \multicolumn{7}{|l|}{ Age at sexual debut } \\
\hline Less than 18 years ${ }^{\text {ref }}$ & 1.000 & - & - & 1.000 & - & - \\
\hline 18 years + & 0.703 & $\mathrm{p}<0.01$ & $0.632-0.781$ & 0.842 & $\mathrm{p}<0.01$ & $0.764-0.927$ \\
\hline \multicolumn{7}{|l|}{ Marital status } \\
\hline Cohabiting ref & 1.000 & - & - & & & \\
\hline Married & 0.934 & 0.897 & $0.328-2.655$ & & & \\
\hline Never married & 1.087 & 0.658 & $0.751-1.572$ & & & \\
\hline \multicolumn{7}{|c|}{ Household wealth group } \\
\hline Poorer ref & 1.000 & - & - & 1.000 & - & - \\
\hline Middle & 2.014 & $\mathrm{p}<0.01$ & $1.612-2.519$ & 1.980 & $\mathrm{p}<0.01$ & $1.605-2.443$ \\
\hline Richer & 1.492 & $\mathrm{p}<0.01$ & $1.193-1.866$ & 1.467 & $\mathrm{p}<0.05$ & $1.066-2.020$ \\
\hline Richest & 0.137 & $\mathrm{p}<0.01$ & $0.008-0.024$ & 0.587 & $\mathrm{p}<0.01$ & $0.486-0.710$ \\
\hline \multicolumn{7}{|l|}{ Family structure } \\
\hline Foster ref & 1.000 & - & - & 1.000 & - & - \\
\hline Nuclear & 0.690 & $\mathrm{p}<0.01$ & $0.572-0.833$ & 0.446 & $\mathrm{p}<0.05$ & $0.213-0.933$ \\
\hline Polygynous & 3.135 & $\mathrm{p}<0.01$ & $2.531-3.884$ & 1.782 & $\mathrm{p}<0.01$ & $1.440-2.204$ \\
\hline Single-parent & 5.254 & $\mathrm{p}<0.01$ & $3.471-7.956$ & 2.882 & $\mathrm{p}<0.01$ & $2.389-3.476$ \\
\hline \multicolumn{7}{|l|}{ Psychoactive drug use } \\
\hline $\mathrm{No}^{\text {ref }}$ & 1.000 & - & - & 1.000 & - & - \\
\hline Yes & 1.292 & $\mathrm{p}<0.05$ & $1.045-1.597$ & 1.782 & $\mathrm{p}<0.01$ & $1.440-2.204$ \\
\hline \multicolumn{7}{|l|}{ Alcoholic consumption } \\
\hline $\mathrm{No}^{\text {ref }}$ & 1.000 & - & - & 1.000 & - & - \\
\hline Yes & 2.161 & $\mathrm{p}<0.01$ & $1.822-2.562$ & 1.359 & $\mathrm{p}<0.05$ & $1.089-1.696$ \\
\hline
\end{tabular}

Notes: (reference category), CI (confidence interval), OR (odds ratio)

\section{DISCUSSION}

This study was designed to identify the drivers of transactional sex in a Nigeria University. The study builds on numerous existing studies that investigated the prevalence and motivations for transactional sex in tertiary institutions of learning across the world. ${ }^{3,7,16-18}$ In the study, the prevalence of transactional sex was $23.85 \%$. This is consistent with the $23.8 \%$ observed in a recent study in another Nigerian University 7 but slightly higher than the $17.6 \%$ prevalence observed in another recent study elsewhere. ${ }^{6}$ The study thus further confirms that transactional sex is prevalent in tertiary institutions in Nigeria. In most cases, transactional sex are perpetrated by men and sustained by young girls and older women who are always willing to exchange sex in fulfilment of several economic or social needs. ${ }^{12,13,19,20}$ Large numbers of undergraduates have already accepted the phenomenon of 'Sugar Daddy or Aristo' as a social practice of giving something-for-something. ${ }^{3,11,17}$ This could be discouraged through behaviour change communication that stressed the importance of moral values and contentment in sexual relationships.

Such practices have serious implications for the sexual and reproductive health of female undergraduates because they usually do not have the power to negotiate safer sex in such sexual relationships because the men are usually older and richer. ${ }^{21-23}$ This further exposes young girls to the risk of both unintended pregnancy and unsafe abortion. In cases where the men are not older, transactional sex still thrives in University campuses because of the expectation of young girls that their male partners should provide their needs while they take care of his sexual needs. ${ }^{14}$ It is thus plausible for the administrators of Nigerian Universities to develop more strategies to promote responsible sexual behaviour of undergraduates through the introduction of compulsory sexual health curriculum as part of the courses to be taken by all university students. There is a possibility that such curriculum will raise awareness about the level and consequences of transactional sex which may translate into reduction in its prevalence among undergraduates in the country. Another possible means of eliminating transactional sex on University campuses is for University administrators to create opportunities of parttime work for students who are not on any scholarship or bursary schemes. This may reduce the need for exchanging sex for economic items on campuses especially among students who do not have supportive families. ${ }^{18}$

It is important that governments in Nigeria should recognise transactional sex as a major form of sexual and reproductive rights violation that endangers the victims. Already, the 2017 National Reproductive Health Policy has included the elimination of transactional sex as part of the target for achieving gender equality and elimination of all forms of discrimination in the country. ${ }^{24}$ However, there is need to strengthen the 
capacity of the Universities by ensuring the provision of youth-friendly services in all University health centers to enable the centers respond promptly to the sexual health needs of undergraduates. The health centers should also be empowered to monitor use of psychoactive drugs in the Universities. Also, governments should take more proactive steps to ensure punishment for all acts of reproductive health violations on University campuses. This may reduce the prevalence of transactional sex by discouraging many others from engaging in the practice.

\section{Limitations}

The study was not able to establish causality between the independent and dependent variables examined. This limitation is peculiar to all cross-sectional studies. However, this does not invalidate the findings because the significant correlations shown in the result suggests that the variables may have both direct and indirect influence on each other. The qualitative reports generated from the study are not presented. This may have provided more support for the findings.

\section{CONCLUSION}

This study identified gender, age, age at sexual debut, household wealth group, family structure, use of psychoactive drugs and alcoholic consumption as key drivers of transactional sex in Nigerian Universities. The study notes that transactional sex has serious implications for the sexual and reproductive health of undergraduates. The need to promote responsible sexual behaviour of undergraduates through the introduction of compulsory sexual health curriculum is imperative in the country. Governments across the country need to strengthen the capacity of Universities health centres to respond promptly to the sexual health needs of undergraduates.

\section{ACKNOWLEDGMENTS}

Authors expressed their gratitude towards all students who participated in the survey.

\section{Funding: No funding sources}

Conflict of interest: None declared

Ethical approval: The study was approved by the Institutional Ethics Committee

\section{REFERENCES}

1. Shefer T, Clowes L, Vergnani T. Narratives of transactional sex on a university campus. Culture, Health and Sexuality. Int $\mathrm{J}$ Res Interven Care. 2012;14(4):435-47.

2. Formson C, Hilhorst D. The many faces of transactional sex: Women's agency, livelihoods and risk factors in humanitarian contexts: a literature review researching livelihoods and services affected by conflict. United Kingdom: Secure Livelihoods Research Consortium; 2016.
3. Tade O, Adekoya AJ. Transactional sex and the 'aristo' phenomenon In Nigerian Universities. Human Affairs. 2012;22:239-55.

4. Ranganathan M, MacPhail C, Pettifor A, Kahn K, Khoza N, Twine R, et al. Young women's perceptions of transactional sex and sexual agency: a qualitative study in the context of rural South Africa. BMC Public Health. 2017;17(666):1-16,

5. Moore AM, Biddlecom AE, Zulu EM. Prevalence and meanings of exchange of money or gifts for sex in unmarried adolescent sexual relationships in subSaharan Africa. Afr J Reprod Health. 2007;11(3):4461.

6. Kassa AW, Ayele BY, Nikus M. Magnitude and Associated Factors of Transactional Sex among High School Students in Debre Markos Town, Northwest Ethiopia. J AIDS Clin Res. 2018;9:768.

7. Ajayi AI, Somefun OD. Transactional sex among Nigerian university students: the role of family structure and family support. PLoS ONE. 2019;14(1):e0210349,

8. Madlala LSM. Transactional sex, HIV and young African women: are we there yet? Future Virol. 2013;8(11):1041-43,

9. Austin KF, Choi MM, Berndt V. Trading sex for security: unemployment and the unequal HIV burden among young women in developing nations. Int Socio. 2017;32(3):343-68.

10. Miller FR, Dunkle K. Constrained relationship agency as the risk factor for intimate partner violence in different models of transactional sex. Afr J AIDS Res. 2017;16(4):283-93.

11. Mampane JN. Exploring the "Blesser and Blessee" phenomenon: young women, transactional sex, and HIV in Rural South Africa. SAGE Open. 2018;1:9.

12. Maganja RK, Maman S, Groves A, Mbwambo JK. Skinning the goat and pulling the load: transactional sex among youth in Dar es Salaam, Tanzania. AIDS Care. 2007;19(8):974-81.

13. Rosenbaum J, Zenilman J, Rose E, Wingood G, Clemente R. Cash, cars, and condoms: economic factors in disadvantaged adolescent women's condom use. J Adolescent Health. 2012;51:233-41.

14. Wamoyi J, Heise L, Meiksin R, Kyegombe N, Nyato $\mathrm{D}$, Buller AM. Is transactional sex exploitative? A social norms perspective, with implications for interventions with adolescent girls and young women in Tanzania. PLoS ONE. 2019;14(4):e0214366.

15. Kyegombe N, Meiksin R, Wamoyi J, Heise L, Stoebenau K, Buller AM. Sexual health of adolescent girls and young women in Central Uganda: exploring perceived coercive aspects of transactional sex. Sexual Reprod Health Matters. 2020;28(1): 1700770 .

16. Nwokocha EE. Transactional sex in Nigerian Universities: social and demographic implications. UNILAG Sociological Rev. 2007;8:57-82.

17. Masvawure T. I just need to be flashy on campus: female students and transactional sex at a university 
in Zimbabwe. culture, health and sexuality. Int $\mathbf{J}$ Research Intervention Care. 2010;12(8):857-70.

18. Ene JC, Okechukwu CU, Anazonwu NP. Transactional sex at the University of Nigeria, Nsukka campus: implications for school social work in Nigeria. J Social Work Developing Societies. 2020;2(1):37-53.

19. Wamoyi J, Wight D, Plummer M, Mshana GH, Ross D. Transactional sex amongst young people in rural northern Tanzania: an ethnography of young women's motivations and negotiation. Reprod Health. 2010;7(2):1-18.

20. Samara S. Something-for-something love: the motivations of young women in Uganda. J Health Organ Management. 2010;24(5):512-9.

21. Cockcroft A, Kunda JL, Kgakole L, Masisi M, Laetsang D, Ho-Foster A, et al. Community views of inter-generational sex: findings from focus groups in Botswana, Namibia and Swaziland. Psychol Health Med. 2010;15(5):507-14.

22. Oyediran KA, Odutolu O, Atobatele AO. Intergenerational sexual relationship in Nigeria: implications for negotiating safe sexual practices. In Letamo G (Ed.) Social and Psychological Aspects of HIV/AIDS and their Ramifications. Croatia: In Tech. 2011.
23. Wamoyi J, Buller AM, Nyato D, Kyegombe N, Meiksin R, Heise L. Eat and you will be eaten: a qualitative study exploring costs and benefits of age disparate sexual relationships in Tanzania and Uganda: implications for girls' sexual and reproductive health interventions. Reprod Health. 2018;15(207):1-11.

24. Federal Ministry of Health. National Reproductive Health Policy 2017. Abuja, Nigeria: FMoH; 2017.

25. Ajayi AI, Owolabi EO, Olajire OO. Alcohol use among Nigerian university students: prevalence, correlates and frequency of use. BMC Public Health. 2019;19(752):1-11.

26. Ajayi AI, Okeke SR. Protective sexual behaviours among young adults in Nigeria: influence of family support and living with both parents. BMC Public Health. 2019;19(983):1-8.

27. Stata Corp. Stata: Release 14. Statistical Software. College Station, TX: Stata Corp LP; 2015.

Cite this article as: Ige OS, Solanke BL. Drivers of transactional sexual relationships among students in a Nigerian University: implications for elimination of reproductive rights violation. Int $\mathbf{J}$ Reprod Contracept Obstet Gynecol 2021;10:55-60. 